\title{
PRODUÇÃO DE ÉSTERES ETÍLICOS A PARTIR DE MISTURAS DE SEBO BOVINO E ÓLEO DE FRITURA POR CATÁLISE ÁCIDA
}

\author{
N. Dolfini ${ }^{1}$, J. V. Berni ${ }^{1}$, V. H. M. A. Abreu ${ }^{1}$, S. H. B. Faria ${ }^{1}$ e N. C. Pereira ${ }^{1}$ \\ ${ }^{1}$ Universidade Estadual de Maringá, Departamento de Engenharia Química \\ Email para contato: nataliadolfini@gmail.com
}

\begin{abstract}
RESUMO - Neste trabalho é apresentado um estudo da aplicação de catalisadores ácidos na produção de ésteres etílicos a partir da blenda de sebo bovino e óleo de fritura, tendo em vista que tais matérias-primas vêm se mostrando uma alternativa econômica e ecologicamente sustentável para a produção de biodiesel. O objetivo desta pesquisa é estudar qual catalisador: ácido sulfúrico e fosfórico promove maior rendimento da reação de transesterificação. Foi observado que a conversão de ácidos graxos em ésteres etílicos foi muito baixa para o ácido fosfórico inviabilizando, portanto, a produção do biodiesel com a utilização deste catalisador.
\end{abstract}

\section{INTRODUÇÃO}

O mundo atual está em constante busca por desenvolvimento sustentável, levando em consideração o que é correto socioambientalmente e o que é economicamente viável. Juntamente com este dilema, vem o crescimento da população mundial, do consumo de alimentos, das indústrias e dos problemas ambientais. (CANESIN, et al., 2004).

Sendo assim, uma das principais alternativas para o desenvolvimento de uma fonte energética sustentável sob os aspectos ambiental, econômico e social é a substituição de combustíveis fósseis por biocombustíveis, fontes energéticas alternativas limpas e renováveis que emitem menos gases poluentes na atmosfera, além de trazer a perspectiva da redução das importações de óleo diesel, gerando divisas para o País (ANP).

\subsection{Objetivo}

Este trabalho tem como objetivo estudar o desempenho de dois de catalisadores ácidos a serem utilizados na reação de transesterificação para produção de ésteres etílicos, tendo como objetivo específico definir o catalisador homogêneo ácido que apresenta a maior eficiência em determinada condição físico-química na reação de produção de biodiesel, obtendo o maior número de ésteres convertidos.

\subsection{O Biodiesel}

Pode ser definido quimicamente biodiesel como um produto biodegradável, não tóxico, constituído por ésteres alquílicos de ácidos carboxílicos de cadeia longa, obtida da transesterificação dos triglicerídeos de óleos e gorduras com alcoóis de cadeia curta, 
comumente o metanol ou etanol, na presença de um catalisador ácido, básico ou enzimático resultando no coproduto glicerol (ARAUJO, 2008; LOBÔ, 2009).

Segundo Christoff (2006), o diesel comercial tem uma porcentagem de enxofre em sua composição, a remoção do mesmo reduz a viscosidade do produto a teores não compatíveis com a especificação e para a correção desse problema, adicionam-se aditivos com o objetivo de lubrificação. A adição do biodiesel no diesel atende as duas necessidades: corrige a deficiência viscosimétrica conferindo a mistura às propriedades lubrificantes vantajosas para o motor e influência na redução dos teores de emissão de compostos sulfurados.

A especificação das misturas de biodiesel/diesel nacional é dada pelo Regulamento Técnico $\mathrm{N}^{\mathrm{o}} 2 / 2006$, sendo que a mesma é requerida para a aprovação do biodiesel produzido no território nacional. Segundo este regulamento, atualmente é obrigatório que $7 \%$ do diesel comercializado sejam provenientes de biodiesel e o restante $(93 \%)$ de derivado do petróleo (ROSENHAIM, 2009).

\subsection{Matérias Primas}

Os biocombustíveis, como o etanol e o biodiesel, são produzidos geralmente a partir de cultivares terrestres antes dedicados à produção de alimentos. O biodiesel é produzido principalmente de oleaginosas, como soja, canola, dendê entre outras. Toda oleaginosa tem suas vantagens e desvantagens, que implicam no rendimento maior ou menor na obtenção do biodiesel. Entretanto, para a melhor destinação final de subprodutos outrora considerados resíduos, utiliza-se como matéria prima de baixo custo, substância tais como o sebo bovino e o óleo de fritura, em um processo catalisado por ácido. A utilização destas matérias-primasfaz com que o biodiesel fique mais competitivo em preço com o diesel de petróleo. Esses potenciais passivos ambientais são significativamente mitigados quando transformados em biodiesel (MACEDO \& NOGUEIRA, 2005; MINISTÉRIO DA AGRICULTURA, 2014).

\subsection{Obtenção de Ésteres Etílicos}

Existem vários tipos de métodos de produção do biodiesel, esterificação, transesterificação, hidrólise, pirólise. A transesterificação e a esterificação estão sendo estudadas por vários pesquisadores e são os métodos de obtenção do biodiesel mais utilizados. A transesterificação é a reação de óleos e gorduras, vegetais ou animais, com um álcool, preferencialmente de cadeia curta, para formar ésteres (biodiesel) e glicerol. Esta reação é possível de ser realizada sem a utilização de catalisadores, mas devido aos baixos rendimentos obtidos e às condições de processo desfavoráveis, o uso de catalisadores se tornou essencial. O álcool de cadeia curta utilizado largamente é o etanol pela sua vantagem econômica e ambiental. (CUNHA, 2008; MACEDO \& NOGUEIRA, 2005)

Os catalisadores utilizados na reação são geralmente classificados em três categorias, ácido, alcalino e enzimático. A matéria-prima escolhida para a obtenção do biodiesel é importante na decisão do catalisador (CUNHA, 2008; MACEDO \& NOGUEIRA, 2005; MARCHETTI, 2005).

Os catalisadores ácidos mais utilizados são os ácidos sulfúrico, sulfônico, fosfórico e clorídrico, sendo empregados quando a matéria-prima utilizada apresenta alto teor de ácidos graxos livres, como o óleo de fritura, contando com algumas desvantagens na sua utilização, como necessitar de temperaturas bastante elevadas e longo tempo de reação, mais de 3 horas, 
necessitam também de grande quantidade de álcool na reação, aumentando o rendimento em ésteres e facilitando a separação do glicerol formado (CUNHA, 2008; MACEDO \& NOGUEIRA, 2005; MARCHETTI, 2005).

\section{MATERIAIS E MÉTODOS}

Neste trabalho foi utilizado óleo de fritura doado pelo restaurante universitário da Universidade Estadual de Maringá e sebo bovino doado pela Graxaria Osso Líder, localizado em Nova Esperança, Paraná. O etanol anidro foi fornecido pela Cocafé (Astorga, Paraná) e o ácido sulfúrico e fosfórico (catalisador) foi obtido pela FMAIA.

O processo de produção de ésteres etílicos foi composto das seguintes etapas: preparação da matéria-prima, caracterização, reação de transesterificação, separação de fases, lavagem do biodiesel, secagem e análise para controle de qualidade desse combustível renovável.

Preparação das matérias-primas: As matérias primas passaram por um processo de aquecimento e filtragem, conforme a metodologia usada pelo Oliveira (2014).

Cromatografia a gás: As matérias-primas foram submetidas à análise em um cromatógrafo marca Thermo Scientific, modelo Trage GC Ultra, com uma coluna da marca SGE Analytical Science, modelo BPX 70, para a análise de perfil de ácidos graxos.

Umidade: A análise de umidade foi feita no departamento de engenharia química da Universidade Estadual de Maringá, Maringá-PR, em aparelho Volumetric Karl Fisher marca Orion, modelo AF8.

Índice de Saponificação e Índice de Acidez: Foram realizados através do método apresentado pela metodologia do Instituto Adolfo Lutz (2008).

Densidade a $20^{\circ} \mathrm{C}$ : A determinação da densidade foi realisada no departamento de física da Universidade Estadual de Maringá, Maringá-Pr. Foi utilizado um densímetro, marca Anton Paar, modelo DMA 5000.

Produção da blenda: A produção da blenda é na proporção de 22:3 (óleo de fritura e sebo bovino), sendo este o resultado de análises do trabalho realizado por Oliveira (2014).

Reação de Transesterificação: Foi utilizada a metodologia do Oliveira (2014), diferenciando o catalisador (sulfúrico e fosfórico) por um planejamento experimental. A lavagem do biodiesel foi feita com água a $90^{\circ} \mathrm{C}$ a fim de retirar impurezas (álcool não reagido, catalisador e sabões formados durante a reação).

Análises de controle de qualidade do biodiesel: Foram realizadas as análises de cromatografia a gás, conforme a metodologia do Oliveira (2014).

\section{RESULTADOS E DISCUSSÃO}

\subsection{Caracterização da matéria-prima}

As Tabelas 1 e 2 a seguir ilustram os resultados de cromatografia gasosa para amostras do sebo bovino, óleo de fritura e blenda produzida a partir da mistura (22:3) dos reagentes. 
Tabela 1 - Caracterização do óleo de fritura residual (cocção) por meio da cromatografia gasosa.

\begin{tabular}{|l|c|c|c|c|}
\hline \multicolumn{5}{|c|}{ ÓLEO DE FRITURA RESIDUAL } \\
\hline & $\begin{array}{c}\text { óleo de } \\
\text { fritura }\end{array}$ & $\begin{array}{c}\text { UZUN, et } \\
\text { al., 2012 }\end{array}$ & $\begin{array}{c}\text { OLIVEIRA, } \\
2014\end{array}$ & $\begin{array}{c}\text { LEUNG, } \\
2006\end{array}$ \\
\hline \multicolumn{1}{|c|}{ Ácido Graxo } & $\%$ & $\%$ & $\%$ & $\%$ \\
\hline Ácido Mirístico (C14:0) & - & - & 0,4 & 0,9 \\
\hline Ácido Palmítico (C16:0) & 14,8 & 7,07 & 11,6 & 20,4 \\
\hline Ácido Palmitoleico (C16:1) & - & - & 0,6 & 4,6 \\
\hline Ácido Heptadecanóico (C17:0) & 3,4 & - & - & - \\
\hline Ácido Esteárico (C18:0) & 14,1 & 2,42 & 3,6 & 4,8 \\
\hline Ácido Oleico (C18:1n9c) & 22,2 & 36,68 & 22,4 & 52,9 \\
\hline Ácido Linoleico (C18:2n6c) & 42,7 & 52,2 & 51,9 & 13,5 \\
\hline Ácido Linolênico (C18:3n3) & 8,7 & - & - & 0,8 \\
\hline Ácido Erucico (C22:1n9) & - & - & 0,8 & 0,07 \\
\hline Outros & - & 0,83 & - & 1,03 \\
\hline
\end{tabular}

Pela Tabela 1, é possível observar que os ácidos linoleico, oleico e palmítico foram encontrados, respectivamente, em maior quantidade na cocção e esta proporção também é encontrada por Uzun e Oliveira, apenas Leung apresentando diferentes resultados.

Tabela 2 - Caracterização do sebo bovino por meio da cromatografia gasosa.

\begin{tabular}{|c|c|c|c|c|}
\hline \multicolumn{5}{|c|}{ SEBO BOVINO } \\
\hline & Sebo & $\begin{array}{c}\text { HEMMAT, } \\
2013\end{array}$ & $\begin{array}{c}\text { OLIVEIRA, } \\
2014\end{array}$ & $\begin{array}{c}\text { DOGAN, } \\
2013\end{array}$ \\
\hline Ácido Graxo & $\%$ & $\%$ & $\%$ & $\%$ \\
\hline Ácido Láurico (C12:0) & - & 0,07 & - & - \\
\hline Ácido Mirístico (C14:0) & 4,1 & 2,64 & 1,4 & $2-8$ \\
\hline Ácido Palmítico (C16:0) & 19,6 & 26,5 & 21,1 & $24-37$ \\
\hline Ácido Esteárico (C18:0) & 25,6 & 0,19 & 26,3 & $14-29$ \\
\hline Ácido Oleico (C18:1n9c) & 51,4 & 61,61 & 42,2 & $40-50$ \\
\hline Ácido Linoleico (C18:2n6) & 3,8 & 3,42 & 2,3 & $1-5$ \\
\hline Ácido Linolênico (C18:3n3) & - & 0,5 & - & - \\
\hline
\end{tabular}

Pela Tabela 2, pode-se ressaltar os ácidos oleico, esteárico e palmítico, que são encontrados em maiores proporções neste trabalho bem como na literatura.

Com os resultados obtidos pela caracterização físico-química do óleo de fritura, sebo bovino e blenda, obteve-se a Tabela 3 . 
Tabela 3 - Caracterização físico-química das matérias-primas.

\begin{tabular}{|c|c|c|c|c|c|}
\cline { 3 - 6 } \multicolumn{2}{c|}{} & $\begin{array}{c}\text { Densidade } \\
(\mathrm{g} / \mathrm{mL})\end{array}$ & $\begin{array}{c}\text { Umidade } \\
(\%)\end{array}$ & $\begin{array}{c}\text { Índice de acidez } \\
(\mathrm{mg} \mathrm{KOH} / \mathrm{g} \text { óleo })\end{array}$ & $\begin{array}{c}\text { Índice de saponificação } \\
(\mathrm{mg} \mathrm{KOH/g} \text { óleo })\end{array}$ \\
\hline \multirow{3}{*}{ Sebo } & nov/14 & 0,898624 & $0,335 \pm 0,24$ & $24,35 \pm 0,07$ & $236,36 \pm 3,79$ \\
\cline { 2 - 6 } & dez/14 & 0,89617 & $0,215 \pm 0,03$ & $24,85 \pm 0,30$ & $224,84 \pm 14,4$ \\
\cline { 2 - 6 } & jan/15 & 0,895686 & $0,118 \pm 0,34$ & $26,12 \pm 0,80$ & $239,44 \pm 0,90$ \\
\hline \multirow{3}{*}{ Óleo } & nov/14 & 0,918721 & $0,346 \pm 0,27$ & $1,92 \pm 0,02$ & $236,14 \pm 5,6$ \\
\cline { 2 - 6 } & dez/14 & 0,918908 & $0,229 \pm 0,03$ & $2,08 \pm 0,5$ & $232,6 \pm 1,7$ \\
\cline { 2 - 6 } & jan/15 & 0,919285 & $0,229 \pm 0,02$ & $2,42 \pm 0,35$ & $226,94 \pm 3,00$ \\
\hline \multirow{3}{*}{ Blenda } & nov/14 & 0,904233 & $0,246 \pm 0,13$ & $4,87 \pm 0,14$ & $226,08 \pm 0,19$ \\
\cline { 2 - 6 } & dez/14 & 0,919513 & $0,202 \pm 0,28$ & $4,89 \pm 0,02$ & $232,22 \pm 0,80$ \\
\cline { 2 - 6 } & jan/15 & 0,875586 & $0,186 \pm 0,01$ & $4,13 \pm 0,16$ & $201,19 \pm 0,31$ \\
\hline
\end{tabular}

\subsection{Caracterização do biodiesel}

O biodiesel foi produzido na proporção de 1:36:0,46 de blenda, etanol e catalisador, respectivamente.

Tabela 4 - Cromatografia gasosa do biodiesel.

\begin{tabular}{|c|c|c|c|}
\hline Acido graxo & $\begin{array}{c}\text { Biodiesel obtido } \\
\text { com Ácido Sulfúrico } \\
\text { Teor: } 94,5 \%\end{array}$ & $\begin{array}{c}\text { Biodiesel obtido com } \\
\text { Ácido Fosfórico } \\
\text { Teor: } 8,1 \%\end{array}$ & $\begin{array}{c}\text { OLIVEIRA, } \\
2014 \\
\text { Teor: } 96,7 \%\end{array}$ \\
\hline Ácido mirístico C14:0 & 1,2 & - & - \\
\hline Ácido palmítico C16:0 & 18,3 & 14,7 & 3,4 \\
\hline Ácido esteárico C18:0 & 8,1 & 10,4 & 2,9 \\
\hline Ácido oleico C18:1n9t & 66,1 & 61,7 & 38,5 \\
\hline Ácido linoleico C18:2n6c & 3,3 & 13,1 & 55,2 \\
\hline Ácido linolênico C18:3n3 & 3 & - & - \\
\hline
\end{tabular}

Com a Tabela 4, pode-se concluir que a catálise ácida de ácido fosfórico não foi vantajosa nestas condições, visto que há grande diferença entre o teor obtido por eles.

É importante ressaltar as diferenças nos aspectos visuais do biodiesel obtido, já que o obtido pela transesterificação com ácido sulfúrico foi de coloração escura, porém límpido, enquanto o obtido por reação com ácido fosfórico foi de cor amarelado, um pouco turvo e com a formação de um produto de fundo indefinido e indesejado.

\section{CONCLUSÃO}

Por este trabalho, podemos concluir que a transesterificação utilizando como catalisador o ácido sulfúrico é a mais vantajosa em comparação com o biodiesel produzido com ácido fosfórico.

Os motivos para este fato podem ser por exemplo: a diferença de força ácida entre os catalisadores e as condições de reação utilizadas neste trabalho, necessitando uma pesquisa aprofundada sobre as causas destes resultados e também sobre o produto de fundo indesejado formado pelo biodiesel produzido com ácido fosfórico. 


\section{Congresso Brasileiro de Engenharia \\ Química em Iniciação Científica \\ Unicamp - Campinas - SP \\ 19 a 22 de julho de 2015}

\section{REFERÊNCIAS}

ANP - Agência Nacional do Petróleo, Gás Natural e Biocombustíveis. Disponível em < http://www.anp.gov.br/?pg=53930\&m=\&t1=\&t2=\&t3=\&t4=\&ar $=\& p s=\&$ cachebust $=13$ 90397911901> Acesso em 20 Jan. 2015

ARAUJO, V. Economic assessment of biodiesel production from waste frying oils. Bioresource Technology, 101, 2010.

CANESIN, E. A; OLIVEIRA, C. C; MATSUSHITA, M; et al,. Characterization of residual oils for biodiesel production. Electronic Journal of Biotechnology. 2004. 39-45.

CHRISTOFF, P. Produção de Biodiesel a partir do óleo residual de fritura comercial. Instituto de Engenharia do Paraná (Mestrado em desenvolvimento de tecnologias). Curitiba, 2006.

CUNHA, M, E; Caracterização de biodiesel produzido com misturas binárias de sebo bovino, óleo de frango e óleo de soja. f.90. (Mestrado em Química) Universidade Federal do Rio Grande do Sul, 2008.

DOGAN, T. H; TEMUR, H. Effect of fractional winterization of beef tallow biodiesel on the cold flow properties and viscosity. Fuel, 2013. P. 793-796.

HEMMAT, Y; GHOBADIAN, B; LOGHAVI, M; et al. Biodiesel Fuel Production From Residual Animal Fat as An Inedible And Inezpensive Feedstock. International Research Jounal of Applied and Basic Sciences, 2013. Vol. 5, p. 84-91.

INSTITUTO ADOLFO LUTZ, Normas Analíticas. Métodos Químicos e Físicos para Análise de Alimentos, v.1, $3^{\mathrm{a}}$ ed., São Paulo, 1985.

LOBÔ, I. P.; FERREIRA, S. L. C.; CRUZ, R. S. Biodiesel: Parâmetros de qualidade e métodos analíticos. Química Nova. v.32, n.6, p.1596 - 1608, 2009.

MACEDO, I. C. \& NOGUEIRA, L. A. H. Cadernos NAE/ Núcleo de Assuntos Estratégicos da Presidência da República - No. 2 (jan. 2005). - Brasília: Núcleo de Assuntos Estratégicos da Presidência da República, Secretaria de Comunicação de Governo e Gestão Estratégica, 2005.

MARChetTi, J. M., Miguel, V. U., ERRAZU, A. F. Possible methods for biodiesel procuction. Renew Sust Energy Rev, 11. P. 1300- 1311. 2007.

OLIVEIRA, Sandro Martins de. BLENDA SEBO BOVINO/OLEO DE FRITURA: Proposta de produção de éster etílico a partir da reciclagem de resíduos. Universidade Estadual de Maringá (Mestrado em bioenergia). Maringá, 2014.

ROSENHAIM, R. Avaliação das propriedades fluído-dinâmicas e estudo cinético por calorimetria exploratória diferencial pressurizada (PDSC) de biodiesel etílico derivado de óleo de fritura usado. f.130. (Tese Doutorado). Universidade Federal da Paraíba, 2009.

UZUN, B. B; KILIÇ, M; OZBAY, N; et. al. Biodiesel production from waste frying oils: Optimization of reaction parameters and determination of fuel properties. Fuel, 2012. P. 347-351.

LEUNG, D. Y. C; GUO, Y. Transesterification of neat and used frying oil: Optimization for biodiesel production. Fuel Processing Technology, 2006. P. 883-890. 